\title{
Deaf mental health: enhancing literacy through a hearing and deaf community collaboration
}

\author{
Saúde mental em pessoas surdas: melhorando \\ a alfabetização por meio da colaboração entre a \\ comunidade surda e ouvinte
}

Salud mental en personas sordas: mejora de la alfabetización mediante la colaboración entre sordos y comunidad escucha

ID Tracey Anne Bone
University of Manitoba, Canada

Abstract: This article explores the process through which findings of a doctoral study became the impetus for the development of a Deaf Mental Health Committee and two community-based events intended to enhance the mental health literacy of the Deaf community in a large metropolitan city in central Canada. The author, a hearing professional and University professor has provided professional counselling services to clients including those who are Deaf and hard of hearing, and conducted a number of studies in and with the Deaf community. Her doctoral study reported on the experience and narratives of a sample of Deaf adults diagnosed with Major Depressive 
Disorder. Participant narratives highlighted gaps in understanding of mental health and mental illness. A goal of enhancing mental health literacy in the Deaf community developed into the establishment of a Deaf Mental Health Committee. This article presents the successes of that Deaf and hearing collaboration.

Keywords: Engagement. Extension. Enrichment.

Resumo: Este artigo explora o processo pelo qual as conclusões de um estudo de doutorado se tornaram o ímpeto para o desenvolvimento de um Comitê de Saúde Mental para Surdos e dois eventos comunitários com o objetivo de melhorar a alfabetização em saúde mental da comunidade Surda em uma grande cidade metropolitana no centro do Canadá. O autor, um profissional da audição e professor universitário, prestou serviços de aconselhamento profissional a clientes, incluindo surdos e deficientes auditivos, e conduziu diversos estudos na comunidade de surdos. Seu estudo de doutorado relatou a experiência e as narrativas de uma amostra de adultos surdos com diagnóstico de transtorno depressivo maior. As narrativas dos participantes destacaram lacunas na compreensão da saúde mental e da doença mental. A meta de aumentar a alfabetização em saúde mental na comunidade Surda desenvolveu-se no estabelecimento de um Comitê de Saúde Mental para Surdos. Este artigo apresenta os sucessos dessa colaboração de surdos e ouvintes.

Palavras-chave: Engajamento. Extensão. Enriquecimento.

Resumen: Este artículo explora el proceso a través del cual los hallazgos de un estudio de doctorado se convirtieron en el impulso para el desarrollo de un Comité de Salud Mental para Sordos y dos eventos comunitarios destinados a mejorar la alfabetización en salud mental de la comunidad sorda en una gran ciudad metropolitana en el centro de Canadá. El autor, un profesional de la audición y profesor 
Deaf mental health: enhancing literacy through a hearing and deaf...

\section{Summary}

For her doctoral study, the author sought to explore the experience and meaning-making narratives of a sample of six Deaf adults from a large, central Canadian city diagnosed with Major Depressive Disorder (BONE, 2014). As we know, effective two-way communication is an essential component of effective assessment, diagnosis and treatment. This sample ultimately reported many of the same symptoms as documented in mental health literature specific to depression reported in the dominant hearing community. Here though is where the experiences diverge. This sample highlighted unique challenges resulting from engaging in a mental health system that is designed around oral communication rather than their dominant visual communication.

The challenges for the participants began far in advance of the actual diagnosis. Participants recalled losing interest in their daily activities or feeling a experiencing a sense of sadness, a sadness that became insidious and began to creep so quietly into all aspects of their lives without apparent reason. Some reported becoming weepy, and retreating to their bedroom or other 'safe space' as a way to avoid social interaction. Others became angry though were often unable to express where their anger originated. At least one participant's substance use accelerated, with that participant later becoming violent with their partner. All of the participants informed the researcher (this author) that at the time they had no idea what was causing their sense of dread, their 'blackness', their sense of disconnect.

The participants in the study shared stories of frustration as they struggled to understand their darkening moods and their dwindling energy. One participant expressed their sense of dread through the metaphor of an overflowing garbage can. They said they felt 
Deaf mental health: enhancing literacy through a hearing and deaf...

their life was 'like a garbage can'; they had so much 'stuff' going on for them, and so many emotions they couldn't explain that their "garbage can was full - and there was no one there to empty it" (BONE, 2014, p. 117) . On the advice of family member, this person finally agreed to seek medical attention to discuss their feelings of 'blackness'. As the person is Deaf and the medical clinic did not have audio visual technology that would have supported the Deaf person contacting them, a hearing family member booked the appointment. Thought booked for a Deaf person, when they arrived, the hearing physician did not have a Sign Language interpreter present. He was also not interested in calling for one to facilitate the effective two-way communication between the two. In fact, according to the Deaf patient, the physician seemed rather annoyed that the person was Deaf as that meant the physician had to conduct his assessment through handwriting. The appointment was understandably unproductive. It left the Deaf patient feeling even more frustrated. A second appointment was made with new physician. This person was familiar with Deaf culture and Sign Language so demanded an ASL-English interpreter be present. It was then that a formal assessment could be completed. That assessment resulted in a diagnosis of Major Depressive Disorder. The diagnosis of Major Depressive Disorder did not resolve the issue however. The Deaf person advised that they, in fact, had not truly understood the diagnosis or the medication prescription. As a result, they stopped the medication after two days because they were feeling 'strange' (BONE, 2014, 139). Yet another participant reported that she had received multiple diagnoses over the years from hearing physicians who refused to engage an interpreter during the assessment phase. These examples clearly indicate that the mental health system failed to meet the language needs of these Deaf individuals, as it failed to meet the needs of all others in the study. 
Deaf mental health: enhancing literacy through a hearing and deaf...

\section{Findings}

All but one of the six participants reported that the medical professional refused to accommodate their request for an ASL-English interpreter to be present in the appointment, rendering much of the communication exchange inaccessible. All participants reported a sense of exasperation that their repeated requests for Sign Language interpretation were refused. Instead, the attending physicians expected their Deaf patients to engage in the physicians' dominant mode of communication; namely written English. These same physicians alternatively assumed an innate competence in their Deaf patients for speechreading. In essence, these participants were describing the experience of audism (HUMPHREY, 1975). Humphrey and Alcorn (1995) define audism as "an attitude based on pathological thinking which results in a negative stigma toward anyone who does not hear; like racism or sexism, audism judges, labels, and limits individual on the basis of whether a person hears and speaks" (p. 85).

Participants in the study (BONE, 2014) reported that mental health promotion and prevention materials were inaccessible. They acknowledged they saw pamphlets in doctors' offices. They also reported viewing infomercials on video screens in these same offices. They reported however, that they often could not understand the content of the pamphlets, and the infomercials were in spoken communication not ASL, rendering them inaccessible. In essence, these participants reported that they had little opportunity to enhance their understanding of mental health or mental illness; or put another way, to enhance their mental health literacy. They lacked the mental health literacy necessary to recognize the symptoms that suggested a mental health problem, or the histo- 
Deaf mental health: enhancing literacy through a hearing and deaf...

Tracey Anne Bone

rical development of their symptoms. This exasperated their frustration and sense of disempowerment as sought to understand what why their world was changing.

\section{Study Conclusion (Bone, 2014)}

The conclusion of the authors' study was revealing, though also consistent with the limited existing literature. Participants reported a common theme of inadequate and inaccessible communication that overrode all other sub-themes. The main theme of inadequate communication originated within the (often)-hearing family, though extended to work settings, and with professionals who lacked cultural awareness of the Deaf culture, or Sign Language. The subthemes of the study included a lack of accessible information on mental illness (i.e. what it is; types of diagnoses; treatments/interventions, etc.); stigma of mental illness within the Deaf community; lack of accessible programming; and the often debilitating impact of gossip in the Deaf community. Also reported was an inadequate number of ASL-English interpreters, and/ or interpreters without specialized mental health training. Lastly, participants reported that services designed for the dominant hearing community were not linguistically accessible. One participant reported that though informed she could commence the program for survivors of childhood sexual abuse, she was told the service could not afford an interpreter. This participant was expected to attend a multi-week session without a language conduit, with little appreciation that the therapeutic content would be linguistically inaccessible. The participant, as noted above, reported their life and experience with depression was like a garbage can; they re- 
Deaf mental health: enhancing literacy through a hearing and deaf...

Tracey Anne Bone

ported a lifetime of experiences of darkness, trauma, and rejection resulting from lack of societal understanding of deafness. This was further complicated as there was no way for this participants to "empty their garbage cans". Another said she saw her physician several times before he diagnosed her with depression. She said with frustration, "why did it take him so long to put the puzzle pieces together?" (BONE, 2014, p. 135). A third said she ate excessively in an attempt to avoid the confusion and pain in her life. "Cake", she said, became her "happy pill" (BONE, 2013, p. 137). All participants felt their negative experiences resulted from a combination of their own lack of knowledge of mental illness and a shared medical/mental health system that viewed their deafness and Deaf identity as pathological rather than as human difference.

\section{8}

\section{A Community Collaboration: Evolution of the Deaf Mental Health Committee}

The findings from the above referenced study (BONE, 2014) revealed significant mental health system and service gaps when considering the mental health needs of the Deaf community. In response to these gaps, the author sought to create a Deaf Mental Health Committee whose task would be to explore culturally appropriate strategies to eliminate or reduce these gaps. The author first contacted a senior member of the local Deaf community in Winnipeg, Manitoba to propose the idea. Mr. Len Mitchell was, at the time, the Student Advisor/Vice-Principal at the Manitoba School for the Deaf, the only bi-cultural bi-lingual school for Deaf and hard of hearing early, middle and senior age students in the province of Manitoba, in central Canada. I discussed the findings 
Deaf mental health: enhancing literacy through a hearing and deaf...

of my study, a study he had been in support of, and the gaps I found. I reported the findings that participants' mental health literacy needs were low, and that each participant in the study reported service delivery gaps. I proposed the creation of a Deaf Mental Health Committee, a committee that would seek ways to fill those knowledge gaps in Deaf mental health literacy. He agreed a conference that would address the low mental health literacy of the Deaf community, associated stigma, and lack of mental health services would be invaluable for members of the Deaf community. He also suggested a second conference designed for professionals to enhance their understanding of the mental health needs of members of the Deaf community. With a goal in mind, we sought to discuss membership of the committee.

The task of identifying potential members of the Deaf Mental Health Committee moved quickly. We both agreed we needed representation from local formal Deaf organizations (i.e. Manitoba Deaf Association) as well as organizations that offer social, cultural, and recreational opportunities for the Deaf community (i.e. Deaf Center Manitoba, Inc.). We also knew representation from the ASL - Deaf Studies program at the local community college was necessary. We agreed representation from the only government-funded support program for Deaf and hard of hearing persons in Manitoba (i.e. then called the Society for Manitobans with Disabilities, now Manitoba Possible) was necessary. Lastly, we agreed that the local office of the Canadian Mental Health Association could serve as an invaluable source of mental health content expertise. Neither of us wanted this to be a politically influenced committee, though too recognized the value of political support in moving the agenda forward with a more comprehensive reach. We discussed a preliminary agenda, and the invitations were sent out to the initial invitees. 
Deaf mental health: enhancing literacy through a hearing and deaf...

The first meeting of the proposed Deaf Mental Health Committee was held in January 2014 at the Deaf Center Manitoba. This author created an agenda and, as founder, chaired the first meeting based on my discussion with my Deaf colleague. To ensure complete two-way communication for all attendees, two ASL-English Interpreters were present at the first meeting. The author covered the interpreter costs for the first meeting, with an agenda item being that of future ASL Interpreter costs.

All invitees attended the meeting. The author, who knew all present at the meeting because of previous work within the Deaf community, presented her research findings, and proposed a Deaf mental health workshop that would support and/or enhance the mental health literacy of the Deaf community in Winnipeg. Support was unanimous. Members of the Deaf community, and hearing members employed supporting Deaf community members agreed that mental health and mental illness was generally poorly understood in the Deaf community. Issues such as lack of accessible information, hearing medical professionals with little to no understanding of Deaf culture or Sign Language, and a lack of programs supports were the primary gaps. At this initial meeting, my colleague reiterated his suggestion that we also consider an independent professional development workshop for those working with the Deaf community. Both proposals received unanimous committee support. This author also proposed the Committee be co-chaired by the author and a member of the Deaf community, to blend the strengths of both communities. This too, received unanimous support. Sheila Montney, then Executive Director of the Deaf Center Manitoba, agreed to assume this role. We formally shared chairperson role throughout the life of the committee, though Ms. Montney assumed the dominant role. 
Deaf mental health: enhancing literacy through a hearing and deaf...

The committee met many times following its inception meeting of January 2014, until the writing of the final financial report in November 2014. The meetings progressed with a focus on coordinating two separate and distinct workshops. The first would be a four-hour workshop designed to meet the mental health literacy needs of the Deaf community, the second a two-day professional development conference. The committee sought funding from two primary sources. The Winnipeg Foundation was the primary funder, with the Manitoba Deaf Association also contributing financially. The sole ASL-Interpreter service in the province of Manitoba offered interpreting services at both events in-kind. The Manitoba School for the Deaf offered the school setting and custodial support at no cost for the professional development workshop. Lastly, all members of the volunteer Deaf Mental Health Committee offered their time gratis.

The DMH working committee was generally a cohesive and collaborative one. One hurdle arose one week prior to the workshop scheduled for Deaf community members. At the time, with food ordered, presenters scheduled, and the location long since booked, only two people were registered to attend. One hearing member of the committee, who had posed some resistance to the event planning throughout, suggested it be cancelled. An honest conversation ensued. All remaining members agreed that two factors were necessary for review. First, all planning was complete and guest speakers confirmed. The Deaf members also noted that low registration was not uncommon in the Deaf community in the days leading up to an event. As a collectivist community, many community members delayed their registration until they had a chance to discuss the event more fully with other members and determine its value. Thankfully all but this one member agreed the event should proceed as scheduled, and it did. 
Deaf mental health: enhancing literacy through a hearing and deaf... Tracey Anne Bone

\section{The Day Arrives - 'Mental Health - Let's Learn: for Deaf Community and Friends' Workshop}

Notwithstanding the two people registered to attend the week prior, a total of 60 people attended the 4-hour Mental Health Let's Learn workshop on September 27, 2014, during International Week of the Deaf (previously Deaf Awareness Week). Held at the Deaf Center Manitoba theatre, the initial response of attendees was not unexpectedly, cautious. Attendees took their seats hesitantly, and carefully scanned the audience for others present. Once the workshop began however, the audience interest ignited, and remained high throughout.

The event began with video Greetings and Introduction from a Deaf counsellor at the Deaf Well-Being Program in British Columbia, Canada. The Deaf Well Being Program is a government funded mental health service created after a multi-year investigation revealed chronic sexual abuse at the only residential school for the Deaf in that province. Funding was established for both the creation of the program, and to ensure its perpetual existence to meet the needs of Deaf people in that province. As the program is well respected across Canada, their inclusion in the workshop was foundational to its success. The program continued with a presentation from the Canadian Mental Health Association on mental health and types of mental illness in general, and mores specifically on the diagnosis of depression. This, and all presentations throughout the workshop were facilitated by ASL-English Interpreters, and tactile interpreters for the Deaf Blind attendees.

Interest in the topic of mental health piqued as participants became more comfortable with the content and their level of understanding improved. That session ended with numerous ques- 
Deaf mental health: enhancing literacy through a hearing and deaf... Tracey Anne Bone

tions from participants. A lunch, funded by the grant from the Winnipeg Foundation provided the opportunity for attendees to engage, and continue to discuss the content in a stigma-free setting. The workshop continued with the author's presentation on her doctoral study in the Deaf community. I intentionally included direct, ASL-translated quotes from the study, carefully protecting the identity of the study participants. My intent was that workshop participants would have an opportunity to relate to the concerns raised by the study participants. This presentation was followed by an attendee engagement session. The author and the committee co-chair posed a series of questions to the audience with an aim of collecting their interest and ideas for future workshops. The response was energetic and ideas captured. The workshop ended with virtual remarks from the Canadian Hearing Society.

This event clearly enhanced the mental health literacy of attendees. It created a forum for beginning to tear down the darkness and walls created by misunderstanding of mental illness in general, and its prevalence overall. Based on the event evaluation, it truly served to enrich the lives of those who felt burdened by their experiences of sadness, confusion, and emotional weariness that often accompanies depression. It allowed some of those who were experiencing sadness at the time, or who had experienced sadness in the past, to release the shackles of stigma and acknowledge that they were not alone in their experiences. All those in the authors' study reported that their biggest fear was that others would 'find out' they were diagnosed with mental illness. They feared the resulting gossip, and the outcome of that gossip. All study participants shared their overwhelming worry that they would be judged as incompetent, and ostracized from their own community. The Deaf mental health literacy workshop allowed all those present to hear that depression was, in fact, common both within the general 
Deaf mental health: enhancing literacy through a hearing and deaf... Tracey Anne Bone

population, and in the Deaf community. It allowed those experiencing sadness or depression to consider lifting the lid on their own personal 'garbage can', and consider speaking with a professional about their experiences. They learned that medication was a common treatment for some with depression, as was counselling or even other approaches. In brief, the workshop helped normalize the experience of depression; with those present learning that mental illness in general knows no demographic boundaries and affects people from all walks of life, age groups, and genders. In essence, this successful partnership between members of the Deaf and hearing communities successfully achieved its aim of enhancing the mental health literacy of the Deaf participants in the workshop.

\section{Professional Development Conference: 'Mental He- alth \& Deaf Community'}

The Deaf Mental Health Committee subsequently created a two-day Professional Development conference for educational, program and other agency-related staff who work with Deaf children and/or adults, as well as family members and university students. The event was well publicized within the local education settings, community based organizations, within the Deaf community itself, and with the municipal and provincial governments. The author also solicited the advertising support from the host of a local radio station. AM 680 CJOB, is accepted as 'Winnipeg's News and Information leader' (Global news, n.d.). The author had been a guest on the Richard Cloutier Live show prior and knew this social justice event would be of interest to him. I requested that the Committee Co-host and I attend. Though he had never had a Deaf 
Deaf mental health: enhancing literacy through a hearing and deaf...

guest on the show, he immediately invited the author, committee co-host and an ASL Interpreter to the broadcast. The co-host was, ultimately not able to attend due to scheduling conflicts, but the opportunity would be have been a unique one for the radio host, and committee co-host. In the author's opinion, this demonstrated but one example of the value of mutual respect and collaboration in advancing social justice issues.

The professional development event was Titled 'Mental Health \& Deaf Community'. The aim of the conference was to "provide valuable insights into culturally proficient and relevant work with Deaf individuals" (conference advertising pamphlet). Held during Mental IIIness Awareness Week 2014, the workshop featured three experts in the field of Deaf mental health, two of us focusing on mental health in Deaf adults, and one focusing on children and youth. A guest speaker from the Canadian Mental Health Association (CMHA) also shared general information about mental health and mental illness. That latter again provided specific information about depression and anxiety, two of the most common diagnoses in the Deaf community. A highlight of the event was the three individual skits from 100 Decibels: a local Deaf Mime Troupe. Following the submission of a grant application jointly completed by the author and Co-Chair of the Deaf Mental Health Committee, the Winnipeg Foundation, founded in 1921, became the major funder for the event (Winnipeg Foundation, 2019). The Manitoba Deaf Association also provided funding. Funding covered the travel costs of the guest speakers, hospitality, speaker gifts, and costs associated with providing accessibility services including ASL interpreters and Note takers for the Deaf, Hard of Hearing and DeafBlind attendees. The Manitoba School for the Deaf also supported the event. They offered space within their building, audiovisual, and custodial support at no cost throughout the two days. Lastly, the committee 
Deaf mental health: enhancing literacy through a hearing and deaf...

members themselves volunteered many hours of planning, set up, and event-day support for this inaugural event.

The conference began with greetings from a member of the Deaf Mental Health Committee on behalf of the committee, and the Deaf community. The Co-Chair of the Deaf Mental Health Committee was the Master of Ceremonies for the event. She welcomed attendees in her first and natural language of American Sign Language. The proceedings of the entire two-day event were available in spoken English, ASL and tactile sign language for the attendees who were DeafBlind.

The two-day event featured several guest speakers. The first, a guest speaker from the Canadian Mental Health Association and, as in the first workshop, introduced the topic of mental health in general. Two guest speakers then addressed the topic of mental health in the Deaf community; the author, and a retired professor. The latter us a child of Deaf adults (CODA) and has devoted his entire career to work with the Deaf community. The formal proceedings of the first day were interspersed with three skits performed by 100 Decibels. These skits, based on the authors' research findings, were titled "Depression"; "(mental health) stigma"; and Deaf culture. A highly respected comedy troupe in Winnipeg and Manitoba, the impact of the skits was indescribable. Not only did the troupe have a platform for highlighting their amazing skills, but also they skillfully brought the pain, isolation, and loneliness commonly associated with depression and stigma to life.

The second day featured a professional who worked with Deaf children and youth. Late deafened, this psychologist gained competency in ASL after losing her own hearing to illness. Attendees also participated in a small group, table discussions about their work within the Deaf community, and a discussion on effec- 
Deaf mental health: enhancing literacy through a hearing and deaf... Tracey Anne Bone

tive strategies when working with this community. The day ended with a panel discussion of the four guest speakers.

A total of 51 people attended the two-day conference held at the Manitoba School for the Deaf. 55\% of the total were Deaf, $33 \%$ hard of hearing and 12\% hearing. Attendees included Manager/Supervisors (15\%), Educators (7\%), and Support workers (9\%). There were also attendees from the local Police Service, Child and Family Services Department, the health sector, local and community service agencies, and community mental health services. Eight members of the Deaf community attended out of general interest.

The evaluations from the event were excellent. $90 \%$ of participants rated the event as "relevant and useful". 85\% of participants rated the table discussions as "had a clear purpose and were useful". The results from the two final questions reinforced the need for this workshop. A full $93 \%$ of participants responded yes to, "Attending the workshop provided me with useful information for my work with Deaf and hard of hearing individuals". Lastly, 91\% of respondents responded yes, when asked, "After this workshop I feel motivated to support future efforts discussed during this workshop".

\section{The Unexpected Impact of Knowledge Dissemination}

The two workshops described above were resounding successes. A collaborative Deaf and hearing partnership resulted in two significant events held to enhance knowledge and understanding. Members of the Deaf community gained new knowledge about the prevalence of mental illness in general, and specific details about depression and its presentation from the Deaf, Let's Learn workshop. They learned about stigma, and self-stigma, and about 
Deaf mental health: enhancing literacy through a hearing and deaf...

the debilitating potential of both. They came to understand that a diagnosis of depression does not mean one has "mental retardation", is "stupid", or is incapable of performing their duties (BONE, 2014). Most importantly, those experiencing symptoms, and those diagnosed with depression, learned they were not alone. Participants at the event began to feel more comfortable finally peeling back their carefully crafted shell of control and appearance, through information that was provided in an accessible way.

Attendees at the two-day professional development workshop gained a more comprehensive understanding of the Deaf mental health experience. Reference was made to existing literature such as that from Australia (QUEENSLAND HEALTH, 2011), and the United States (FELINGER, HOLZINGER, POLLARD, 2012). They also learned about Best Principles when working with Deaf and hard of hearing people (QUEENSLAND HEALTH, 2011). Most importantly, participants reported they gained new knowledge about the challenges many Deaf people face, and the impact of inaccessible mental health services for the Deaf community.

The conference had an unintended outcome. Shortly after the two-day event, the author, who was also in private practice at the time, was contacted by the mother of a member in the Deaf community. She reported that her daughter had experienced discrimination when attempting to seek medical care at a local hospital after experiencing suicidal thoughts. The mother reported hospital staff informed them that the hospital would not provide an ASL-English interpreter for the consult. Their rationale was that none was available at that time. Coincidentally, a second adult woman contacted the author to inform that here request for an ASL-English interpreter was also refused after she presented at the hospital with suicidal thoughts. Both felt powerless at the time, 
Deaf mental health: enhancing literacy through a hearing and deaf...

and furious that they respective requests for Sign Language accommodation were refused. Perhaps unbeknownst to the medical staff at the two hospitals, the decisions to refuse Sign Language interpreters for the delivery of medical services to a Deaf person is a violation of Section 15(1) of the Canadian Charter of Rights and Freedoms (See Eldridge v British Columbia). A landmark court case of 1997 resulted in a decision by the Supreme Court of Canada (Eldridge v British Columbia (AG), [1997] 3 SCR 624) that included the right of deaf persons to Sign Language interpretation when necessary for communication when seeking medical care (CORNISH, FARADAY, 1998).

Following a discussion with both women, the author suggested we meet with the provincial Minister for Family Services to discuss these two distinct violations of Section 15(1) of the Charter of Rights and Freedoms. Both agreed. I contacted the Ministers' office to book audience with her. I requested an ASL-English Interpreter be present to accommodate the first language of both members of the Deaf community. The request was granted without hesitation. In brief, the author, who as a former public servant was familiar with governmental procedures, facilitated an opportunity for the two Deaf community members to share their horrifying experiences resulting from a violation of their language rights under the law. The provincial Minister respectfully heard their concerns and the following day issued an internal memo reminding medical services of the rights of Deaf people to access Sign Language interpreters for medical care.

The successful outcome of this meeting resulted from a respectful relationship between the author, a hearing Social Work professor, and members of the Deaf community (BENEDICT, SASS-LEHRER, 2007). The author offered to engage with resources and 
Deaf mental health: enhancing literacy through a hearing and deaf...

formal systems she was familiar with and serve as the conduit between the governmental process and the concerns raised by the Deaf community. Hospital service providers were reminded of their constitutional expectation to provide ASL-Interpreting services when requested by Deaf people to facilitate medical care.

\section{Conclusion}

One participant in the author's 2013 study reported emphatically, "Yes, that is exactly my point! Things that are out there in the hearing community are not out there in the Deaf community" (BONE, 2014, p. 145). This article intended to report on but one example of the outcome of a successful partnership between the hearing author, and friends and colleagues of the Deaf community. The author's original engagement in the Deaf community began as a desire to enhance her own understanding of Deaf culture and Sign Language as the youngest sister of a Deaf family member. Those relationships grew to be based on a shared understanding, mutual respect, and respectful engagement.

The opportunity to work together in the events on which this article is based clearly demonstrates the impact of merging Deaf and hearing relationships and partnerships. The authors' initial engagement in and with the Deaf community began out my own desire to learn. It has grown into the authors' deepened understanding and respect for the Deaf community and Deaf culture. These relationships and partnerships have extended my knowledge and appreciation, and enriched both my personal and professional life in so many ways. Our continued partnerships remain today. 
Deaf mental health: enhancing literacy through a hearing and deaf... Tracey Anne Bone

\section{References}

BENEDICT, BETH S; SASS-LEHRER, MARILYN. DEAF AND HEARING PARTnerships: Ethical and communication considerations. American Annals of the DeAF, 152(3). 275-282, 2007. Dol: 10.1353/Aad.2007/0023.

BOne, Tracey Anne. Coping With mental illness: Using case study reSeArch to explore Deaf depression narratives. 2013. 258 sheets. Thesis (Doctorate in Social Work) - Faculty of Social Work, University of ManiTOBA, WINNIPEG, 2014.

CORnish, Mary; Faraday, Fay. Eldridge V British Columbia: Defining the Equality Charter Rights of the Disabled under the Charter, 1998. AvalLABLE IN: HTTPS://WwW.CAVALLUZZO.COM/DOCS/DEFAULT-SOURCE/PUBLICATIONS/1999-01-01-ELRIDGE-V-BRITISH-COLUMBIA---DEFINING-EQUALITY-(MARY-CORNISH)-CHARTER-LAW-AND-HUMAN-RIGHTS.PDF?SFVRSN=32FC55D5_2. ACCESS IN: 10 AGO. 2019.

FELINGER, J.; HOLZINGER, D.; POLLARD, Robert. Mental heAlth of deaf people. The Lancet, 379, 1037-1044, 2012.

GLOBAL NEWS. 680 - CjOB, Winnipeg's News \& Information Leader, N.D. Avallable In: htTPS://GLobalnews.ca/RaDio/cjob/. Access In: 10 ago. 2019.

HUMPHREY, Tom. The making of a Word: Audism. UnPUblished ARTICLE SUbmitTed to CLC2001 Readings, 1975. Avallable In: Flle:///C:/Users/UmBONET/DOWNLOAdS/TOMS-AUDISM.PDF. ACCESS IN: 10 Ago. 2019.

HUMPHREY, Tom; ALCORN, B. So you want to be AN interpreter: AN introduction to sign language interpreting. Amarillo, TX: H \& H PublishING, 1995.

MANITOBA SCHOOL FOR THE DEAF (MSD). (N.D.). WeLCOME. MSD.CA. 
Deaf mental health: enhancing literacy through a hearing and deaf... Tracey Anne Bone

QUEENSLAND HEALTH. Working With People Who are Deaf or hard of hearing. Deafness and mental health service. Version 16, 2011. Available IN: HTTPS://METROSOUTH.HEALTH.QLD.GOV.AU/SITES/DEFAULT/FILES/CONTENT/DEAFNESS-MENTAL-HEALTH-WORKING-WITH.PDF. ACCESS IN: 10 AGO. 2019.

THE WINNIPEG FOUNDATION. Your community foundation. For GOod. Forever, 2019. Avallable In: hTtPS://WWW.WPGFDn.org/. ACCESS IN: 10 AGO. 2019.

22

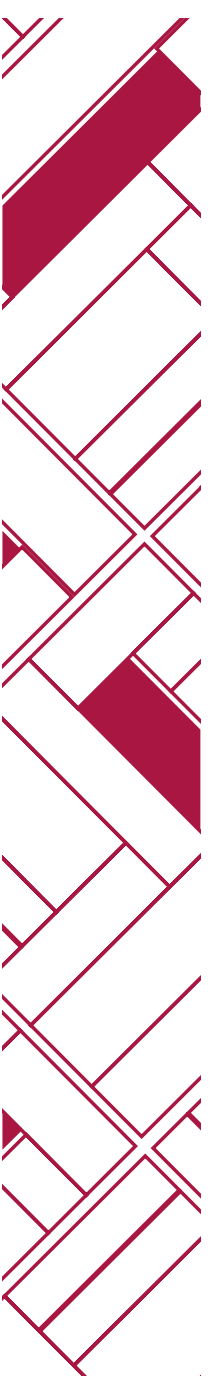

